doi: 10.2306/scienceasia1513-1874.2014.40.420

\title{
Phenolic acid composition and anticancer activity against human cancer cell lines of the commercially available fermentation products of Houttuynia cordata
}

\author{
Thanaset Senawong ${ }^{\mathrm{a}, \mathrm{b}, \mathrm{c}, *}$, Somprasong Khaopha $^{\mathrm{a}}$, Suwatchai Misuna $^{\mathrm{a}}$, Jeeranan Komaikul ${ }^{\mathrm{a}}$, \\ Gulsiri Senawong $^{\mathrm{a}}$, Paweena Wongphakham ${ }^{\mathrm{a}}$, Sirinda Yunchalard ${ }^{\mathrm{d}}$ \\ ${ }^{a}$ Department of Biochemistry, Faculty of Science, Khon Kaen University, Khon Kaen 40002 Thailand \\ b Natural Products Research Unit, Faculty of Science, Khon Kaen University, Khon Kaen 40002 Thailand \\ ${ }^{\text {c }}$ Food and Products Chemical Analysis Research Group, Faculty of Science, Khon Kaen University, \\ Khon Kaen 40002 Thailand \\ ${ }^{d}$ Department of Biotechnology, Faculty of Technology, Khon Kaen University, Khon Kaen 40002 Thailand
}

*Corresponding author, e-mail: sthanaset@kku.ac.th

\begin{abstract}
A number of Houttuynia cordata fermentation products are commercially available in Thailand. However, their anticancer activity remains to be investigated. In this study, the phenolic acid composition and anticancer activity of two commercialized $H$. cordata fermentation products were investigated. Reversed phase HPLC was used to identify and quantify phenolic acids. MTT and Annexin V staining assays were used to investigate antiproliferative and apoptosis induction activities, respectively. Seven phenolic acids including protocatechuic, $p$-hydroxybenzoic, vanillic, syringic, $p$-coumaric, ferulic, and sinapinic acids were detected in the water-soluble constituents of both fermentation products 1 and 2. Water-soluble constituents of fermentation product 2 containing a greater phenolic acid content were more effective than product 1 in inhibiting the growth of HeLa, HCT116, and HT29 cells in a dose- and time-dependent manner. The non-cancer cell line Vero cells appeared to be resistant to both fermentation products. The growth inhibitory effects of both fermentation products in HeLa, HCT116, and HT29 cells included induction of apoptosis. These results suggest that commercially available fermentation products of $H$. cordata contain several anticancer phenolic acids that may be beneficial in the treatment of human cancer.
\end{abstract}

KEYWORDS: antiproliferative activity, fermented foods, apoptosis, colon cancer, cervical cancer

\section{INTRODUCTION}

Mortality rate of Thai population caused by cancers ranks the top among other causes of death per 100000 population ${ }^{1}$. Chemotherapy is an effective way to treat many types of cancers but the cost of treatment with powerful chemicals is a major public health concern in developing countries. Anti-cancer drugs used to treat patients often are expensive and most of them cause negative side effects, especially to normal cells that have a high proliferation rate, affecting most cancer patients. Cancer chemotherapy aims to cure the disease or to extend human life, however, most cancer patients confront suffering from both the disease itself and side effects induced by the treatment. The expensive cost of chemotherapeutic drugs is a dilemma for patients in low-income countries. Accordingly, a herbal medicine for cancer treatment is still an inevitable option.

Houttuynia cordata Thunb., a medicinal plant known in Thai as 'phlu khao', is generally used as a local vegetable in the northern and northeastern regions of Thailand. As a medicinal plant, it has been reported to possess important biological properties such as anticancer $^{2-7}$, antiviral ${ }^{8,9}$, antioxidant ${ }^{10,11}$, and antiinflammatory activities ${ }^{12,13}$. In Thailand, many of $H$. cordata fermentation products are commercially available, however, the anticancer activity of these commercialized products remains to be investigated. Although anticancer activities of water and ethanolic extracts of the plant have been studied intensively, little is known regarding anticancer activity of the fermentation products. The ethanolic extract of yeastand ethanol-fermented $H$. cordata has been shown to exhibit a greater extent of toxicity to human leukaemia cell lines than the non-fermented plant ${ }^{2}$. In addition, Kwon and Ha demonstrated that fermentation process increase the flavonoid content and fermentation products of $H$. cordata inhibit the growth of hepatocellular carcinoma cell line (HepG2 cells) ${ }^{14}$. 
Table $1 \mathrm{pH}$ values and plant ingredients of two commercially available fermentation products and serving suggestion.

\begin{tabular}{lcll}
\hline Fermentation products & $\mathrm{pH}$ & Plant ingredients $^{*}$ & Serving suggestion $^{*}$ \\
\hline FP1 & 3.32 & $\begin{array}{l}\text { H. cordata } \text { Thunb., 60\% }(\mathrm{w} / \mathrm{w}) \\
\text { Kaempferia pandurata Roxb., 15\% (w/w) }\end{array}$ & $\begin{array}{l}15 \mathrm{ml} \text { diluted with } 250 \mathrm{ml} \text { water, twice a } \\
\text { day, in the morning and before bedtime } \\
\text { FP2 }\end{array}$ \\
\hline
\end{tabular}

* The information is taken from the label on the container of the fermentation products.

Four flavonoid compounds (rutin, hyperoside, quercitrin, and quercetin) were reported as major bioactive ingredients in $H$. cordata ${ }^{15,16}$. Two new compounds, houttuynoside A and houttuynamide A, and 38 known compounds have been also identified from a whole plant methanolic extract ${ }^{17}$. Nonetheless, phenolic acid composition of a plant fermentation product has not been investigated. For the above reason, the present study examines the antiproliferation and apoptosis induction of human cervical cancer cell line (HeLa cells), human colon cancer cell lines (HT29 and HCT116 cells), and a non-cancer cell line (Vero cells) by two commercially available fermentation products of $H$. cordata. In addition, some phenolic acids are identified and their contents determined in the water-soluble constituents of the plant fermentation products.

\section{MATERIALS AND METHODS}

\section{Materials}

Fermentation product 1 (FP1) was obtained from a local herbal shop in Khon Kaen province, Thailand. Fermentation product 2 (FP2) was obtained from Prolac (Thailand) Co., Ltd. in Lamphun province, Thailand. The information on their plant ingredients and serving suggestion were obtained from the label on their containers (Table 1). Most chemicals including the pure standards of phenolic acids were obtained from Sigma-Aldrich Corporation (St. Louis, MO, USA), whereas $m$-hydroxybenzaldehyde and p-hydroxybenzoic acid were purchased from Fluka (Buchs, Switzerland) and Acros Organics (Geel, Belgium), respectively.

\section{Preparation of lyophilized fermentation products}

To determine and compare phenolic acid composition and anticancer activity of the two commercially available fermentation products, lyophilized powders of $H$. cordata fermentation products were prepared. Twenty millilitres of each fermentation product were filtered through Whatman grade no. 1 filter paper and centrifuged at $5000 \mathrm{~g}$ for $15 \mathrm{~min}$. The supernatant containing water-soluble constituents was lyophilized to obtain a crude lyophilized fermentation product. Lyophilization of $20 \mathrm{ml}$ of water-soluble constituents gave yields of $1.54 \pm 0.06 \mathrm{~g}$ and $0.25 \pm 0.04 \mathrm{~g}$ for FP1 and $\mathrm{FP} 2$, respectively.

\section{Phenolic acid extraction}

The lyophilized fermentation product (water-soluble constituents) of $1 \mathrm{~g}$ was extracted in $200 \mathrm{ml}$ of $70 \%$ methanol and stirred continuously for $12 \mathrm{~h}$ at room temperature. The mixture was filtered through Whatman grade no. 1 filter paper. The filtrate was evaporated to $60 \mathrm{ml}$ by a rotary evaporator. Further extraction of free and esterified phenolic acids from the $60 \mathrm{ml}$-filtrate was performed as previously described $^{18}$.

\section{HPLC analysis}

The individual phenolic acids in lyophilized fermentation products were identified by using a Waters HPLC system as previously described ${ }^{18}$. The amount of individual phenolic acids in samples was determined by using a standard curve between the concentration of phenolic acid standards $(0.5,1,2,3,4$, and $5 \mu \mathrm{g})(x$-axis) and the ratio between peak areas of the phenolic acid standard and the internal standard ( $m$-hydroxybenzaldehyde; $1 \mu \mathrm{g}$ ) ( $y$-axis).

\section{Cell culture}

HeLa, HCT116, HT29, and Vero cells were obtained from Dr P. Picha (National Cancer Institute, Bangkok, Thailand), Dr O. Tetsu (University of California, San Francisco, US), and Dr S. Barusrux (Khon Kaen University, Khon Kaen, Thailand). All cell lines were cultured at $37^{\circ} \mathrm{C}$ in a humidified atmosphere with $5 \% \mathrm{CO}_{2}$ and maintained in RPMI-1640 medium supplemented with $10 \%$ foetal bovine serum, penicillin (100 U/ml), and streptomycin $(100 \mu \mathrm{g} / \mathrm{ml})$ (GibcoBRL).

\section{Antiproliferative activity assay}

To assess cell growth inhibition, 3-(4,5-dimethylthiazol-2-yl)-2,5-diphenyltetrazolium bromide (MTT) assay ${ }^{19}$ was used. Briefly, cells at a cell density of 
$10^{4}$ cells/well were seeded in a 96-well plate and incubated for $24 \mathrm{~h}$. Different concentrations (0.32$7.70 \mathrm{mg} / \mathrm{ml}$ ) of lyophilized fermentation products were added to the cells and incubated for 48 and $72 \mathrm{~h}$. Vehicle control groups were added with double distilled water. After exposing the cells to the lyophilized fermentation products, the medium was removed, and the cells were incubated with MTT (Sigma Chemical Co., St Louis, MO) $(0.5 \mathrm{mg} / \mathrm{ml}$ in PBS $)$ for $2 \mathrm{~h}$. DMSO was used to dissolve the formazan dye, which was detected by a microtitre plate reader (Bio-Rad Laboratories, Hercules, CA, USA) at $550 \mathrm{~nm}$. A reference wavelength used in this study was at $655 \mathrm{~nm}$. The production of formazan dye was proportional to the number of viable cells.

\section{Apoptosis analysis}

Vybrant Apoptosis Assay Kit \#2 (Molecular Probes, Invitrogen Corporation, Carlsbad, CA, USA.) was used to assess apoptosis induction activity according to the manufacturer's instructions. Briefly, cells were seeded at $1.2 \times 10^{6}$ cells $/ 4 \mathrm{ml}$ in a $5.2-\mathrm{cm}$ dish, incubated for $24 \mathrm{~h}$, and treated with different concentrations of the samples for $24 \mathrm{~h}$. Cells were harvested and stained with Alexa Fluor 488-Annexin V and propidium iodide (PI) as previously described ${ }^{19}$. The flow cytometry results were compared with conventional cell count and morphology under a fluorescence microscope.

\section{Statistical analysis}

Data from three replicated experiments are expressed as mean \pm standard deviation (SD). Statistical analysis was carried out using SPSS 11.5 for windows (SPSS Corporation, Chicago, IL, USA). Significant differences between vehicle controls and sample treated cells were analysed by using one-way ANOVA with Duncan's post hoc test. The $p<0.05$ was set for statistical significance.

\section{RESULTS}

After lyophilization, the yields of $1 \mathrm{ml}$-water-soluble constituents of FP1 and FP2 were $77.0 \pm 3.0$ and $12.5 \pm 2.0 \mathrm{mg}$, respectively. In this study, the lyophilized water-soluble constituents of both fermentation products were used to investigate their phenolic acid composition and anticancer activity.

\section{Phenolic acid composition}

Some phenolic compounds in the extract of this plant have been described ${ }^{15-17}$, however, the phenolic acid composition in the commercialized fermentation products has not yet been determined. Preliminary
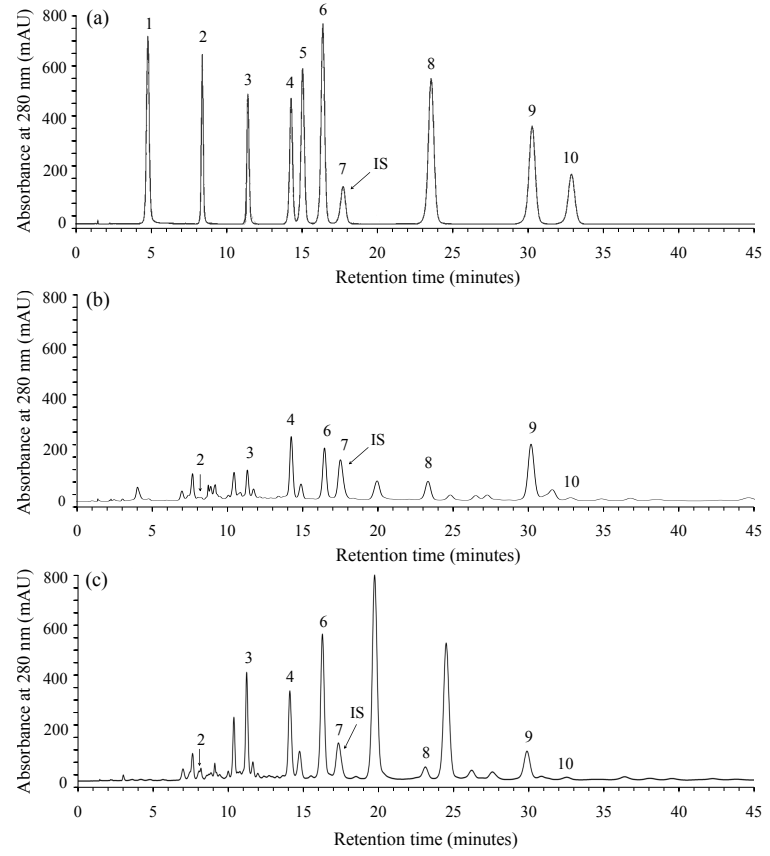

Fig. 1 HPLC chromatograms of phenolic acid standards and two commercially available fermentation products of $H$. cordata. HPLC profiles of (a) standard phenolic acids (1 $\mu \mathrm{g}$ each): 1, gallic acid; 2, protocatechuic acid; 3, p-hydroxybenzoic acid; 4, vanillic acid; 5, caffeic acid; 6, syringic acid; $7, m$-hydroxybenzaldehyde; $8, p$-coumaric acid; 9, ferulic acid and 10, sinapinic acid, and (b, c) FP1 $(1.57 \mathrm{mg})$ and FP2 $(0.35 \mathrm{mg})$ added with the internal standard (IS), $m$-hydroxybenzaldehyde ( $1 \mu \mathrm{g}$ ), are displayed comparatively. The data shown are representatives of two independent experiments performed in duplicate.

separation and identification of individual phenolic compounds in water-soluble constituents of two commercialized fermentation products were conducted by reversed phase HPLC. Fig. 1 shows typical chromatograms of phenolic acid standards and phenolic extracts of two lyophilized fermentation products (water-soluble constituents). Seven phenolic acids including protocatechuic, $p$-hydroxybenzoic, vanillic, syringic, $p$-coumaric, ferulic, and sinapinic acids, were identified in the water-soluble constituents of both FP1 (Fig. 1b) and FP2 (Fig. 1c). Among the identified phenolic acids of FP1 and FP2, the predominant phenolic acids were vanillic and syringic acids, respectively (Table 2). The confirmation of sample peaks was obtained by liquid chromatography-mass spectrometry analysis (data not shown). However, two major sample peaks of FP2 remains to be identified (Fig. 1c). According to HPLC results, the total amount of phenolic acids in water-soluble constituents 
Table 2 Phenolic acid compositions of water-soluble constituents of two commercially available fermentation products of Houttuynia cordata.

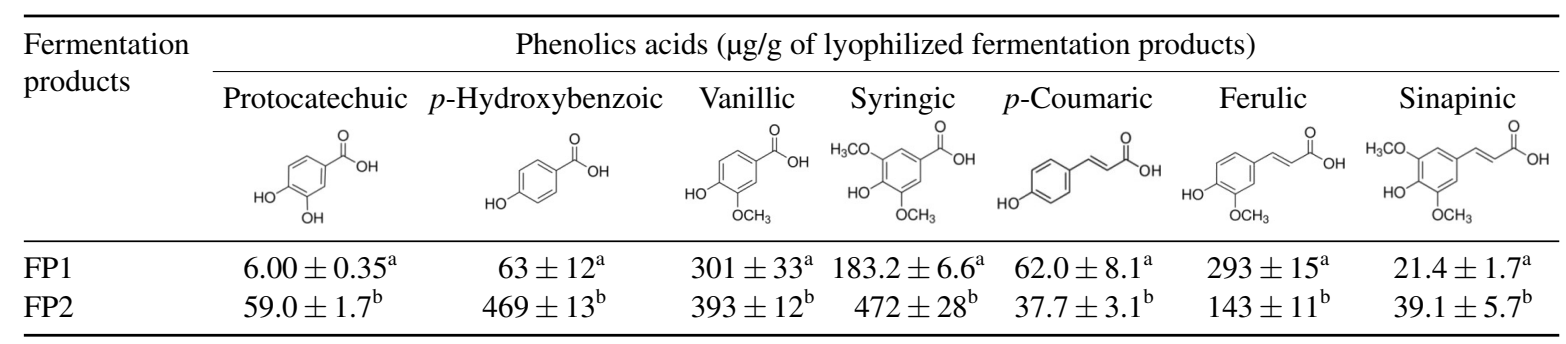

Values are means $\pm \mathrm{SD}$ of three experiments performed in duplicate.

Different superscript letters within the same column indicate significant differences $(p<0.05)$.

of FP2 appeared to be greater than that of FP1 (Fig. 1 and Table 2). Among all identified phenolic acids in water-soluble constituents of FP1, only $p$-coumaric and ferulic acids were detected in a greater quantity than in FP2 (Table 2).

\section{Fermentation product effect on the proliferation of human cancer cell lines}

The lyophilized water-soluble constituents of two commercially available fermentation products were investigated for their antiproliferative activity by MTT method, a conventional tetrazolium-based colorimetric cell proliferation assay. In this study, three human cancer cell lines (HeLa, HCT116, and HT29 cells) and a non-cancer cell line (Vero cells) were used. As shown in Fig. 2, lyophilized water-soluble constituents of both fermentation products inhibited the proliferation of all cancer cell lines tested in a concentration- and time-dependent manner. The lyophilized water-soluble constituent of FP2 demonstrated a greater efficacy in killing all cancer cell lines tested at both 48- and 72-h exposures (Fig. 2b, Fig. 2d, and Fig. 2f). The lyophilized water-soluble constituent of FP2 at less than $2 \mathrm{mg} / \mathrm{ml}$ was not cytotoxic to a non-tumourous cell line (Fig. 2h). Based on an $\mathrm{IC}_{50}$ (half maximal inhibitory concentration) of greater than $8 \mathrm{mg} / \mathrm{ml}$ at both 48- and 72-h exposures, the lyophilized water-soluble constituent of FP1 was considered non-cytotoxic to a non-cancer cell line (Fig. 2g).

\section{Fermentation product effect apoptotic induction}

To further confirm that induction of apoptosis underlies antiproliferative effect of the two commercially available fermentation products, their capacity to induce apoptosis in cancer cell lines was examined. As shown in Fig. 3a, the lyophilized water-soluble constituent of FP2 exhibited a dose-dependent induction of apoptosis in cervical cancer cell line (HeLa cells) for 24-h exposure time in which early apoptotic cells (panels Q4) were increased up to $21 \%$ and $37 \%$ at concentrations of 4 and $6 \mathrm{mg} / \mathrm{ml}$, respectively. In contrast, the treatment of HeLa cells with FP1 for $24 \mathrm{~h}$ resulted in the increase of early apoptotic cells only $6 \%$ and $6 \%$ at concentrations of 4 and $6 \mathrm{mg} / \mathrm{ml}$, respectively. Both fermentation products demonstrated a greater efficacy on apoptosis induction of HCT116 and HT29 cells (Fig. 3b). Apparently, FP2 exhibited a greater efficacy than FP1 on apoptosis induction of all cancer cell lines tested. FP1 and FP2 were the most effective in inducing apoptosis in HT29 and HCT116 cells, respectively. The non-cancer cell line (Vero cells) appeared to be resistant to an induction of apoptosis by each fermentation product (Fig. 3b). These results suggest that $H$. cordata fermentation products suppress the growth of HeLa, HCT116, and HT29 cells at least in part through induction of apoptosis.

\section{Effect of phenolic acids on cell proliferation}

Some identified phenolic acids including $p$-coumaric, ferulic, and sinapinic acids have been previously shown to inhibit the growth of some cancer cell lines ${ }^{18,20,21}$. To further confirm that these identified phenolic acids underlie the antiproliferative effect found in the two commercially available fermentation products, the antiproliferative activities of $p$-coumaric, ferulic, and sinapinic acids against all three cancer cell lines were examined. The MTT assay (Table 3) show that $p$-coumaric, ferulic, and sinapinic acids could inhibit the growth of HeLa, HCT116, and HT29 cells at millimolar concentrations. p-Coumaric acid exhibited the greatest antiproliferative activity against all three cancer cell lines. Notably, all three phenolic acids were less toxic to the non-cancerous Vero cell line. This finding suggested that $p$-coumaric, ferulic, and sinapinic acids may underpin, at least in part, anticancer activity of the $H$. cordata fermentation products. 

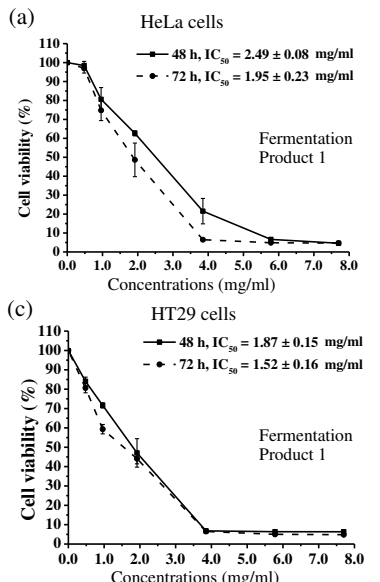

(e)
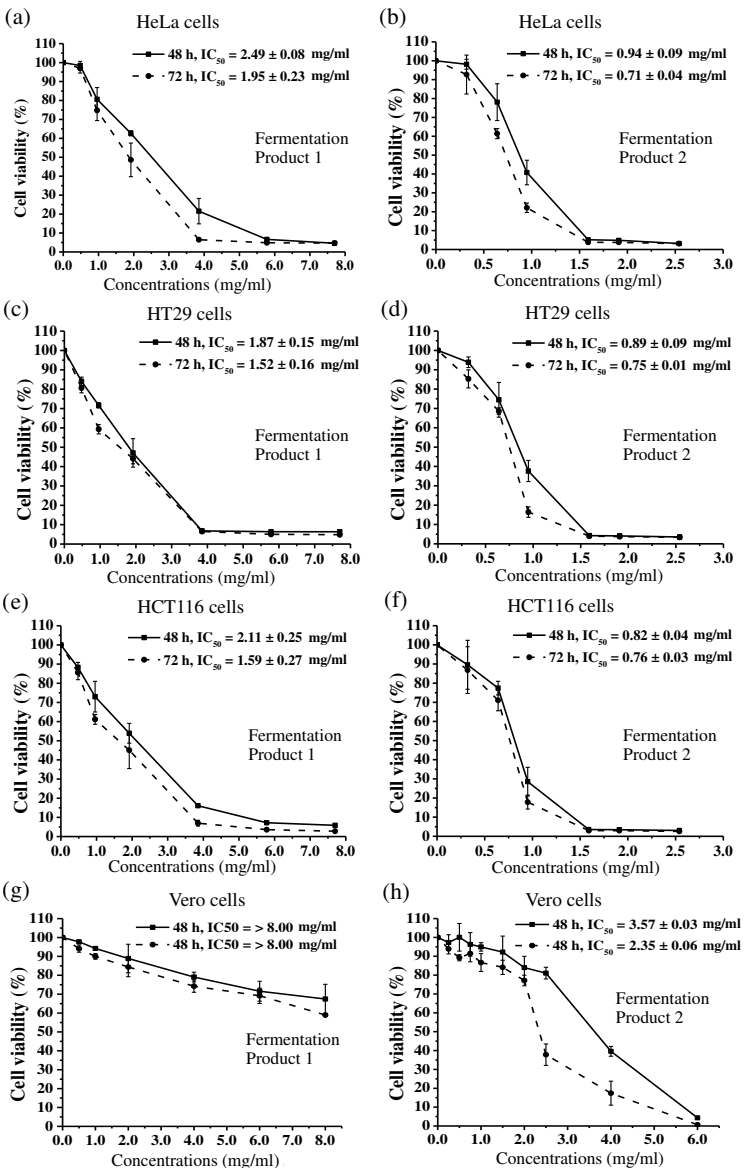

(d)

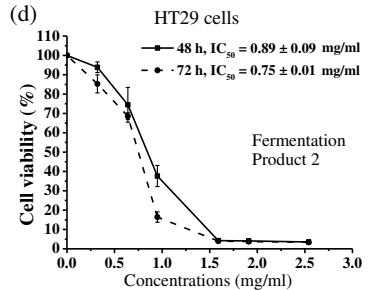

(f)

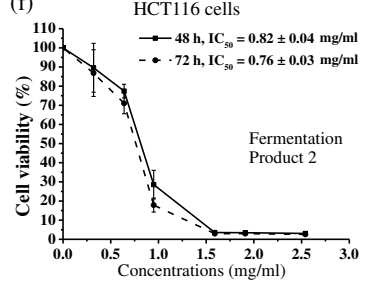

(h)

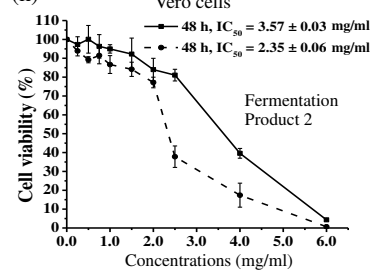

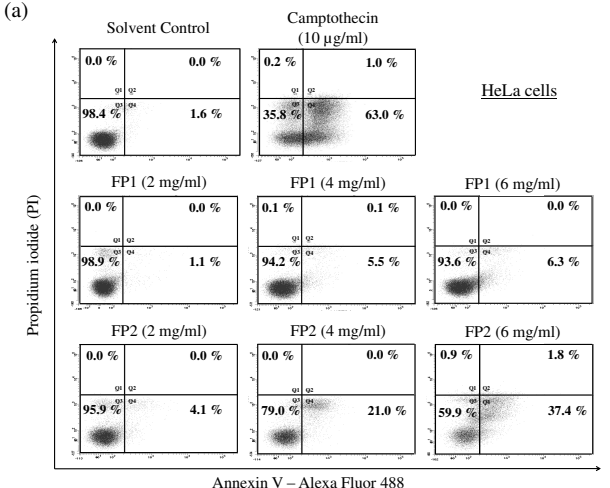

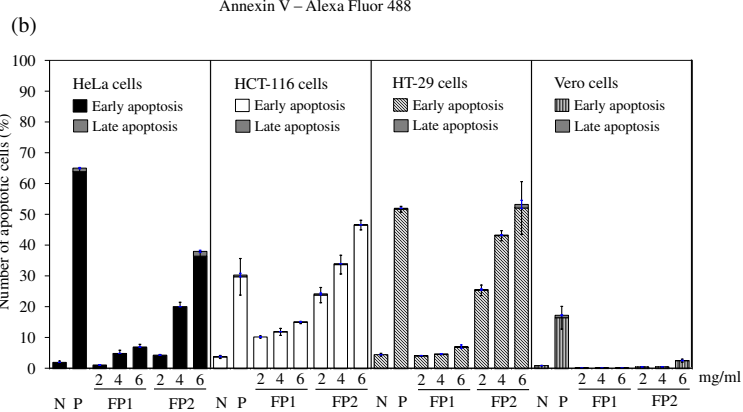

Fig. 3 Apoptotic death analysis by flow cytometry of noncancer and cancer cells treated with the commercially available $H$. cordata FP1 and FP2. (a) Representative dot plots display the apoptotic death of HeLa cells treated with the indicated concentrations. After 24 h-treatment, cells labelled with Alexa Fluor 488 Annexin V and propidium iodide (PI) were analysed by flow cytometry to determine the percentage of cells displaying an increase in early (panels Q4) and late (panels Q2) apoptosis. (b) Bar graph shows the amounts of apoptotic noncancer and cancer cells summarized from two independent experiments performed in duplicate. Cells treated with water (solvent control) and camptothecin $(10 \mu \mathrm{g} / \mathrm{ml})$ were used as negative $(\mathrm{N})$ and positive (P) controls, respectively.

cells), and ( $\mathrm{g}, \mathrm{h}$ ) non-cancer cell line (Vero cells), treated for 48 and $72 \mathrm{~h}$. Data were calculated as percentages of cell growth with respect to the solvent control (water), which was defined as $100 \%$ growth, and the results were shown as mean $\pm \mathrm{SD}$ from three different experiments performed in duplicate. The half maximal inhibitory concentration $\left(\mathrm{IC}_{50}\right.$ values) from each experiment were estimated by plotting $x-y$ and fitting the data with a straight line (linear regression). The average $\mathrm{IC}_{50}$ values from 3 independent experiments were calculated and presented along with a line graph.

\section{DISCUSSION}

The expensive cost of cancer chemotherapy afflicts many patients in developing countries. The use of herbal medicine for cancer treatment is therefore still an inevitable option in low-income countries. Poor patients struggle to save their lives using traditional medicinal plants containing unknown active ingredients. A number of phenolic compounds were identified from a whole plant methanolic extract of $H$. cordata $^{17}$, including protocatechuic, $p$-hydroxybenzoic, and vanillic acids. Consistently, these phenolic compounds were also detected in both water-soluble constituents of FP1 and FP2 (Fig. 1). We have investigated the profiles of phenolic acids in water-soluble constituents of the fermentation products because they represent water-soluble crude extracts of the two fermentation products normally consumed by patients and healthy consumers as a dietary supplement. To our knowledge, this is the first time that phenolic acid profiles of commercially available $H$. cordata 
Table 3 Antiproliferative activities of three phenolic compounds found in $H$. cordata fermentation products against human cancer cell lines for $72 \mathrm{~h}$-treatment.

\begin{tabular}{|c|c|c|c|c|c|}
\hline \multirow[t]{2}{*}{ Compounds } & \multirow{2}{*}{$\begin{array}{l}\text { Molar mass } \\
\qquad(\mathrm{g} / \mathrm{mol})\end{array}$} & \multicolumn{4}{|c|}{$\mathrm{IC}_{50}$ values $^{\mathrm{a}}($ mean $\pm \mathrm{SD} ; \mathrm{mM} ; n=3)$} \\
\hline & & Vero cells ${ }^{\mathrm{b}}$ & HeLa cells & HT29 cells & HCT116 cells \\
\hline$p$-Coumaric acid & 164.16 & $2.94 \pm 0.07$ & $0.79 \pm 0.08$ & $0.97 \pm 0.18$ & $1.34 \pm 0.08$ \\
\hline Ferulic acid & 194.18 & $2.80 \pm 0.06$ & $1.51 \pm 0.04$ & $2.20 \pm 0.24$ & $2.13 \pm 0.04$ \\
\hline Sinapinic acid & 224.21 & $>3$ & $2.04 \pm 0.06$ & $2.87 \pm 0.10$ & $2.69 \pm 0.01$ \\
\hline
\end{tabular}

${ }^{\mathrm{a}} \mathrm{IC}_{50}$ values represent concentrations of the indicated compounds that inhibit $50 \%$ of cell proliferation.

${ }^{\mathrm{b}}$ Non cancer cells

fermentation products have been described. Although phenolic acid profiles of the two fermentation products appears to be similar (Fig. 1), a difference in their phenolic acid contents was observed. This difference may be due to different manufacturing processes. Furthermore, the difference may also be due to the presence of a $K$. pandurata Roxb. medicinal plant $(15 \%$; w/w) in H. cordata FP1 (Table 1). Future studies are needed to elucidate the phenolic acid profiles of other commercially available fermentation products to provide more comprehensive data, which would be beneficial for both cancer patients and healthy consumers.

Based on our findings that $H$. cordata fermentation products possessed antiproliferative activity (Fig. 2), one may envision a role for the plant fermentation products in a folk medicine for cancer treatment. As a single-drug treatment, water-soluble constituents of the plant fermentation products were not appreciably potent, however, the combination treatment with other anticancer drugs/medicinal plants may lead to the development of effective therapeutic strategies. The lower phenolic acid content of FP1 (Table 2) may contribute to its lower efficacy in antiproliferative activity compared to FP2 (Fig. 2). Recently, sinapinic acid has been shown to possess histone deacetylase (HDAC) inhibitory activity and inhibit the growth of HeLa, HT29 and HCT116 cells ${ }^{18}$. Protocatechuic acid has been reported to exhibit antiproliferative activity against HL-60 leukaemia cells through induction of apoptosis ${ }^{22} . p$-Coumaric acid detected in water-soluble constituents of both FP1 and FP2 has been shown to inhibit the growth of HCT15 and HT29 cells by inducing apoptosis through ROS-mitochondrial pathway ${ }^{20}$, inhibit the growth of Caco-2 cells by inducing a G2/M phase cell cycle arrest $^{23}$, and inhibit tumour growth in vivo through the inhibition of angiogenesis ${ }^{24}$. Syringic acid has been shown to exhibit cytotoxic activity against A549 lung cancer cells ${ }^{25}$, whereas ferulic acid was reported to have antiproliferative and apoptosis induction activi- ties towards a bladder cancer cell line (T24 cells) ${ }^{21}$. Consistently, $p$-coumaric, ferulic, and sinapinic acids were found to exhibit antiproliferative activity against HeLa, HCT116 and HT29 cells at millimolar concentrations, and $p$-coumaric acid was the most effective compounds in killing both cervical cancer cells (HeLa cells) and colon cancer cells (HCT116 and HT29 cells) (Table 3). Interestingly, sinapinic ${ }^{18}$, $p$-coumaric ${ }^{26}$, and ferulic acids were all found to possess HDAC inhibitory activity (unpublished data), and one could imagine that HDAC inhibition by these compounds may lead to hyperacetylation of histone proteins in cancer cells. Although the link between hyperacetylation and apoptosis is not fully understood, treatments with HDAC inhibitors usually lead to apoptosis induction ${ }^{27}$. Notably, inhibition of HDAC activity in cancer cells is a promising mechanism for cancer therapy ${ }^{27}$. The presence of the abovementioned phenolic acids in both FP1 and FP2 therefore may, at least in part, underpin their anticancer activity. There was no published record in PubMed regarding the effective cytotoxic activity of $p$-hydroxybenzoic and vanillic acids, however, the derivatives of $p$-hydroxybenzoic acid exhibited both HDAC inhibitory and anticancer activities ${ }^{28}$. Nonetheless, the possibility that other unidentified compounds (Fig. 1) and flavonoids ${ }^{15,16}$ found in this plant might underpin the antiproliferative activity of the plant fermentation products cannot be excluded.

Induction of cancer cell apoptosis is a beneficial mechanism for cancer treatment. In this study, the externalized phosphatidylserine, a key "eat-me" signal of apoptotic cells ${ }^{29}$, was detected by a combined Annexin V/PI dual staining assay to confirm the cancer cell death via apoptotic mode. FP2 showed a greater apoptotic activity than FP1 in all cancer cell lines tested (Fig. 3), suggesting that manufacturing process dramatically affected the quality of plant fermentation products. Sinapinic, $p$-coumaric, and ferulic acids have been shown to induce apoptosis of cancer cells ${ }^{18,20,21}$, thus they may at least in part contribute 
to apoptosis-induction capacity of $H$. cordata fermentation products.

In conclusion, the results in this report demonstrated that water-soluble constituents of two commercially available fermentation products had different anticancer activity and their antiproliferative activity seem to correspond to the amount and composition of phenolic acids. The growth inhibitory effect on a cervical cancer cell line (HeLa cells) and colon cancer cell lines (HCT116 and HT29 cells) of both fermentation products is in accordance with their capability to induce cancerous cell apoptosis. Further investigation will provide more details about flavonoid content, HDAC inhibitory activity, and anticancer activity in combination with other anticancer drugs of commercially available fermentation products. Theoretically, our findings may validate the use of $H$. cordata fermentation products as alternative medicine in cancer treatment.

Acknowledgements: This study was supported by the Faculty of Science research grant and KKU Researcher development grant, Khon Kaen University, Thailand. Komaikul J. was supported by a graduate fellowship from the Prolac (Thailand) Co., Ltd., Lamphun, Thailand. We are thankful to Dr Prasan Swatsitang for providing some phenolic acid standards.

\section{REFERENCES}

1. Bureau of Health Policy Strategy (2010) Death rates by leading cause of death per 100,000 population, Thailand, 2006 and 2010. In: Public Health Statistics 2553. Ministry of Public Health, pp 75-6.

2. Banjerdpongchai R, Kongtawelert P (2011) Ethanolic extract of fermented Thunb induces human leukemic HL-60 and Molt-4 cell apoptosis via oxidative stress and a mitochondrial pathway. Asian Pac J Canc Prev 12, 2871-4.

3. Lai KC, Chiu YJ, Tang YJ, Lin KL, Chiang JH, Jiang YL, Jen HF, Kuo YH, Agamaya S, Chung JG, Yang JS (2010) Houttuynia cordata Thunb extract inhibits cell growth and induces apoptosis in human primary colorectal cancer cells. Anticanc Res 30, 3549-56.

4. Pawinwongchai J, Chanprasert S (2011) Antileukemic activity of Houttuynia cordata Thunb. extracts in Jurkat and U937 human leukemic cells. J Chem Pharmaceut Res 3, 204-12.

5. Prommaban A, Kodchakorn K, Kongtawelert P, Banjerdpongchai R (2012) Houttuynia cordata Thunb. fraction induces human leukemic Molt-4 cell apoptosis through the endoplasmic reticulum stress pathway. Asian Pac J Canc Prev 13, 1977-81.

6. Tang YJ, Yang JS, Lin CF, Shyu WC, Tsuzuki M, Lu CC, Chen YF, Lai KC (2009) Houttuynia cordata Thunb. extract induces apoptosis through mitochondrial-dependent pathway in HT-29 human colon adenocarcinoma cells. Oncol Rep 22, 1051-6.

7. Zhou NN, Tang J, Chen WD, Feng GK, Xie BF, Liu ZC, Yang D, Zhu XF (2012) Houttuyninum, an active constituent of Chinese herbal medicine, inhibits phosphorylation of HER2/neu receptor tyrosine kinase and the tumor growth of HER2/neu-overexpressing cancer cells. Life Sci 90, 770-5.

8. Chen X, Wang Z, Yang Z, Wang J, Xu Y, Tan RX, Li E (2011) Houttuynia cordata blocks HSV infection through inhibition of NF-KB activation. Antivir Res $\mathbf{9 2}$, 341-5.

9. Ren X, Sui X, Yin J (2011) The effect of Houttuynia cordata injection on pseudorabies herpes virus (PrV) infection in vitro. Pharmaceut Biol 49, 161-6.

10. Kusirisin W, Srichairatanakool S, Lerttrakarnnon P, Lailerd N, Suttajit M, Jaikang C, Chaiyasut C (2009) Antioxidative activity, polyphenolic content and antiglycation effect of some Thai medicinal plants traditionally used in diabetic patients. Med Chem 5, 139-47.

11. Toda S (2005) Antioxidative effects of polyphenols in leaves of Houttuynia cordata on protein fragmentation by copper-hydrogen peroxide in vitro. J Med Food $\mathbf{8}$, 266-8.

12. Han EH, Park JH, Kim JY, Jeong HG (2009) Houttuynia cordata water extract suppresses anaphylactic reaction and IgE-mediated allergic response by inhibiting multiple steps of FceRI signaling in mast cells. Food Chem Toxicol 47, 1659-66.

13. Kim J, Park CS, Lim Y, Kim HS (2009) Paeonia japonica, Houttuynia cordata, and Aster scaber water extracts induce nitric oxide and cytokine production by lipopolysaccharide-activated macrophages. J Med Food 12, 365-73.

14. Kwon RH, Ha BJ (2012) Increased flavonoid compounds from fermented Houttuynia cordata using isolated six of Bacillus from traditionally fermented Houttuynia cordata. Toxicol Res 28, 117-22.

15. Xu X, Ye H, Wang W, Yu L, Chen G (2006) Determination of flavonoids in Houttuynia cordata Thunb. and Saururus chinensis (Lour.) Bail. by capillary electrophoresis with electrochemical detection. Talanta $\mathbf{6 8}$, 759-64.

16. Wu LS, Si JP, Yuan XQ, Shi XR (2009) Quantitative variation of flavonoids in Houttuynia cordata from different geographic origins in China. Chin J Nat Med 7, 40-6.

17. Chou SC, Su CR, Ku YC, Wu TS (2009) The constituents and their bioactivities of Houttuynia cordata. Chem Pharmaceut Bull 57, 1227-30.

18. Senawong T, Misuna S, Khaopha S, Nuchadomrong S, Sawatsitang P, Phaosiri C, Surapaitoon A, Sripa B (2013) Histone deacetylase (HDAC) inhibitory and antiproliferative activities of phenolic-rich extracts derived from the rhizome of Hydnophytum formicarum Jack.: sinapinic acid acts as HDAC inhibitor. $B M C$ Complement Altern Med 13, 232. 
19. Mosmann T (1983) Rapid colorimetric assay for cellular growth and survival: application to proliferation and cytotoxicity assays. J Immunol Meth $\mathbf{6 5}, 55-63$.

20. Jaganathan SK, Supriyanto E, Mandal M (2013) Events associated with apoptotic effect of $p$-Coumaric acid in HCT-15 colon cancer cells. World J Gastroenterol 19 , 7726-34.

21. Peng CC, Chyau CC, Wang HE, Chang CH, Chen KC, Chou KY, Peng RY (2013) Cytotoxicity of ferulic acid on T24 cell line differentiated by different microenvironments. Biomed Res Int 2013, ID 579859.

22. Anter J, Romero-Jiménez M, Fernández-Bedmar Z, Villatoro-Pulido M, Analla M, Alonso-Moraga A, Muñoz-Serrano A (2011) Antigenotoxicity, cytotoxicity, and apoptosis induction by apigenin, bisabolol, and protocatechuic acid. J Med Food 14, 276-83.

23. Janicke B, Hegardt C, Krogh M, Önning G, Åkesson B, Cirenajwis HM, Oredsson SM (2011) The antiproliferative effect of dietary fiber phenolic compounds ferulic acid and $p$-coumaric acid on the cell cycle of Caco-2 cells. Nutr Canc 63, 611-22.

24. Kong CS, Jeong CH, Choi JS, Kim KJ, Jeong JW (2013) Antiangiogenic effects of $p$-coumaric acid in human endothelial cells. Phytother Res 27, 317-23.

25. Karthik G, Vijayakumar A, Natarajapillai S (2014) Preliminary study on salubrious effect of syringic acid on apoptosis in human lung carcinoma A549 cells and in silico analysis through docking studies. Asian J Pharmaceut Clin Res 7, 46-9.

26. Waldecker M, Kautenburger T, Daumann H, Busch C, Schrenk D (2008) Inhibition of histone-deacetylase activity by short-chain fatty acids and some polyphenol metabolites formed in the colon. J Nutr Biochem 19, 587-93.

27. Marks PA, Xu WS (2009) Histone deacetylase inhibitors: Potential in cancer therapy. $J$ Cell Biochem 107, 600-8.

28. Seidel C, Schnekenburger M, Dicato M, Diederich M (2013) Antiproliferative and proapoptotic activities of 4-hydroxybenzoic acid-based inhibitors of histone deacetylases. Canc Lett 343, 134-46.

29. Ravichandran KS (2010) Find-me and eat-me signals in apoptotic cell clearance: progress and conundrums. J Exp Med 207, 1807-17. 